Revista de

Contabilidade e

Organizações

www.rco.usp.br
DOI: http://dx.doi.org/10.11606/rco.v11i31.134817
Journal of

Accounting and

Organizations

www.rco.usp.br

\title{
A Petrobrás nas teias da corrupção: mecanismos discursivos da mídia brasileira na cobertura da Operação Lava Jato
}

Petrobras in the webs of corruption: discursive mechanisms in the Lava Jato investigation covered by the Brazilian media

Cintia Rodrigues de Oliveira Medeiros ${ }^{\mathrm{a}}$; Rafael Alcadipani da Silveira ${ }^{\mathrm{b}}$

${ }^{a}$ Universidade Federal de Uberlândia

${ }^{b}$ Fundação Getulio Vargas

Palavras-chave

Corrupção.

Mídia.

Lava Jato.

Petrobrás.

\begin{abstract}
Resumo
Nesse artigo, nosso objetivo é explorar a construção e o delineamento de escândalos de corrupção pela mídia no caso da Operação Lava Jato, que tornaram a Petrobrás protagonista de um dos maiores escândalos de corrupção do Brasil. Nossa análise foi feita na cobertura dada, na versão online, de duas publicações brasileiras (Folha de S.Paulo e Revista Veja) em uma grounded theory na vertente construtivista. Como resultados, analisamos o caso estudado em quatro elementos da teoria dos escândalos, e identificamos dois mecanismos discursivos utilizados pela mídia analisada. O primeiro desses mecanismos atua na dimensão do evento, colocando inicialmente a Petrobrás no centro do escândalo, e o outro configura a natureza política do mesmo. Propõe-se que a mídia articula discursos de modo a construir sentidos.
\end{abstract}

Informações do Artigo

Recebido: 28 de julho de 2017

Aceito: 09 de janeiro de 2018

\begin{abstract}
In this paper, our objective is to explore the discursive mechanisms of online media in Lava Jato investigation that have made Petrobrás the protagonist of one of the biggest corruption scandals in Brazil. Our analysis is based on the media coverage of two national publications (Folha de S.Paulo and Veja Magazine), in a grounded theory in a constructivist perspective. As results, we analyze the case studied in four elements of the theory of scandals and we identify two discursive mechanisms used by the analyzed media. One that acts in the dimension of the event, initially placing Petrobrás at the center of the scandal, and the other that constitutes its political nature. It is proposed that the media articulate discourses in order to construct meanings.
\end{abstract}

\section{Implicações práticas}

Eventos de corrupção se tornam escândalos pela repercussão dos discursos divulgados pela mídia. No caso da Petrobrás, dois mecanismos de discurso colocaram a empresa no centro da narrativa do evento, que assumiu uma natureza política. Escândalos como algo construído socialmente alerta os gestores que suas ações de ética e transparência podem proteger a imagem corporativa.

Copyright (C) 2017 FEA-RP/USP. Todos os direitos reservados

\section{INTRODUÇ̃̃̃O}

Em março de 2014, os principais jornais do país noticiaram que estava em curso uma investigação sobre um esquema de corrupção envolvendo a Petrobrás. Desde então, os meios de comunicação vêm publicando matérias sobre a chamada Operação Lava Jato como sendo um dos maiores escândalos de corrupção do país que envolve a estatal, grandes empreiteiras e partidos políticos. 
Recordando a história recente do Brasil, casos de corrupção são frequentes e, desde que o escândalo do "Mensalão" veio a público, em 2005, vários outros casos de corrupção engrossam a lista de grandes escândalos políticos no país ${ }^{1}$. Diante desse contexto, é de se esperar que os escândalos de corrupção ocupem espaço e interesse na agenda de pesquisadores e de organizações. Todavia, ainda que o palco, onde são protagonizados os escândalos de corrupção, sejam objeto de estudos desse campo, essa temática foi abordada marginalmente e apenas recentemente recebeu uma maior atenção (Oberoi, 2014), com espaços em periódicos científicos (Ashforth, Gioia, Rovinson, \& Treviño, 2008; Holan, Zyglidopoulos, \& Hirsch, 2017) e em eventos acadêmicos.

Neste artigo, nós buscamos responder à seguinte questão: como a mídia nacional on-line contribui para construção, delineamento ou ampliação do escândalo de corrupção revelado na Operação Lava Jato? Nosso objetivo é explorar o delineamento de escândalos de corrupção pela mídia on-line sobre a Operação Lava Jato, que tornaram a Petrobrás protagonista de um dos maiores escândalos de corrupção brasileiros. Nossa análise recai sobre a cobertura da mídia realizada por duas publicações nacionais, Folha de S.Paulo e Revista Veja, em suas versões on-line. Para explorar o material empírico empregamos a análise qualitativa, utilizando recursos da grounded theory em sua vertente construtivista (Charmaz, 2011). Ao apontar como a mídia opera na produção de escândalos envolvendo corporações, nosso artigo contribui para o estudo das organizações por considerar dois pontos: (1) a sociologia da corrupção e a sociologia dos escândalos estão imbricadas (Grü, 2008), pois a corrupção é uma violação às normas que, quando revelada, torna-se um escândalo cujas proporções dependem da cobertura da mídia; e (2) a mídia tem participação ativa na construção e delineamento dos escândalos (Adut, 2005), envolvendo organizações e indivíduos que reagem de forma a minimizar as consequências negativas do escândalo. Além disso, nossa análise do esquema de corrupção que envolve a Petrobrás é de natureza críticoconstrutivista, estando concentrada no modo como o esquema de corrupção tornou-se um escândalo produzido pela mídia nacional on-line.

\section{ABORDAGENS TEÓRICAS DA CORRUPÇÃO}

Embora a corrupção tenha sido considerada como objeto na sociologia e ciência política há mais de 30 anos, ainda não se tem uma definição universalmente aceita para o termo. A corrupção é um fenômeno social multifacetado, e tem sido definida de diferentes formas. O programa 'Global Programme Against Corruption' (GPAC, 2001) das Nações Unidas, a Transparência Internacional (TI, 2015) e o Banco Mundial (World Bank, 2006) relacionam corrupção com o abuso do poder exercido para obtenção de ganhos privados, assim como Batabyal e Chowdhury (2015). O fato é que a literatura sobre corrupção atrai interesses de campos diversos, e a citada falta de consenso sobre o que seja corrupção se deve, em parte, aos problemas relacionados às diferenças legais e culturais entre as nações (Gardiner, 1970; Heidenheimer, 1970; Power \& Gonzáles, 2003; Maeda \& Ziegfeld, 2015). Considerando as dificuldades de se chegar a esse consenso, Gardiner (1970); Heidenheimer (1970) e Hodgkinson (1997) reúnem diversas definições em torno de um foco principal, as quais são apresentadas na Tabela 1.

Tabela 1. Síntese das definições de corrupção de acordo com diferentes perspectivas

\begin{tabular}{ll}
\hline Foco & Definição para Corrupção \\
\hline Perspectiva Legal & $\begin{array}{l}\text { Ato oficialmente proibido por leis estabelecidas pelo governo. Comportamentos que desviam } \\
\text { das normas e regulamentações legais. }\end{array}$ \\
Interesse público & $\begin{array}{l}\text { Padrão de comportamento que se afasta das normas predominantes em um dado contexto, cuja } \\
\text { principal motivação é a obtenção de ganhos privados. } \\
\text { Opinião pública }\end{array}$ \\
O ato corrupto é definido pela população, desde que consistente com as instituições formais. \\
Centrada no mercado & $\begin{array}{l}\text { Uso ilegal de mecanismos de mercado em decisões alocativas, estabelecidas à parte do sistema } \\
\text { político democrático, para maximizar decisões com base nos princípios e leis de mercado. }\end{array}$ \\
Centrada no cargo & $\begin{array}{l}\text { Comportamento que se desvia dos deveres formais de um cargo público em razão de vantagens } \\
\text { pecuniárias ou de status oferecidas a seu titular, familiares ou amigos íntimos. }\end{array}$ \\
público & $\begin{array}{l}\text { Definida pelas práticas tradicionais e percepções culturais construídas historicamente. } \\
\text { Histórico-cultural }\end{array}$ \\
Realista & $\begin{array}{l}\text { coletivo) que desafia o statesmanship (político com habilidade e trânsito para integrar relações } \\
\text { entre instituições e organizações exercendo fontes de poder tanto coercitivas como persuasivas). }\end{array}$ \\
\hline Fonte:
\end{tabular}

Fonte: Elaborado pelos autores com base em Gardiner (1970), Heidenheimer (1970) e Hodgkinson (1997).

${ }_{1}^{1}$ UOL. Pelo menos 11 escândalos de corrupção sacudiram o país desde mensalão; relembre. 05/06/2015. http://noticias.uol.com.br/politica/ ultimas-noticias/2015/06/05/pelo-menos-11-escandalos-de-corrupcao-sacudiram-pais-desde-mensalao-relembre.htm 
Além das propostas conceituais, a literatura sobre corrupção compreende estudos sobre suas causas, consequências, tipologias, entre outros subtemas. Os antecedentes da corrupção são estudados no nível macro (país) e micro (indivíduo) ou conjugando ambos os níveis (O’Connor \& Fischer, 2012). Em nível macro os fatores econômicos, políticos, socioeconômicos, culturais e históricos explicam porque a corrupção ocorre, e em nível micro, a corrupção é explicada pelas características (sóciodemográficas, valores, atitudes e normas) do indivíduo que tem o comportamento corrupto. Considerado, pela Transparência Internacional (TI, 2015), um dos maiores desafios do mundo contemporâneo, a corrupção é um obstáculo à democracia e ao estado de direito, sendo capaz de paralisar esforços de desenvolvimento de uma nação, visto que impede a atuação do bom governo, distorce as políticas públicas, ocasiona a má alocação de recursos, prejudica o setor privado e, particularmente, atinge os mais pobres.

A literatura sobre corrupção se desenvolveu com poucos estudos empíricos (Oberoi, 2014), o que pode ser explicado pela dificuldade de coletar dados e, ainda, pelo fato de a corrupção e as redes sociais, que a envolvem, representarem um tipo de sociedade secreta (Warren, 2001; Numerato, 2015). Para Simmel (1906), as sociedades secretas constituem em uma forma de informação na sociedade moderna, sendo organizadas com base em princípios de confiança e proteção recíprocas, e do conhecimento sobre fatos mantidos ocultos dos não membros. No entanto, o segredo é sempre acompanhado pela possibilidade de ser revelado e, quando isso ocorre, conforme Cobb e Taylor (2015), o escândalo gerado toma proporções que dependem do modo como a mídia atua na revelação e cobertura dos fatos que representam transgressões.

\section{ABORDAGENS TEÓRICAS DO ESCÂNDALO}

Na década de 1990, começa a tomar corpo a sociologia dos escândalos (Jacobsson \& Löfmarck, 2008; Grün, 2008), acompanhada, principalmente, pelos estudos em comunicação e em ciência política (Silva, 2013). Esta literatura procurava teorizar típicos fenômenos sociais de intensa dramaticidade, que pode mobilizar intensa energia emocional e, muitas vezes, com sérias consequências (Adut, 2005). Os escândalos surgem quando são revelados comportamentos que violam normas sociais ou legais e eram, até então, desconhecidos do público, sendo definidos por Esser e Hartung (2004, p. 1041) como a "intensa comunicação pública sobre uma falha real ou imaginária que é por consenso condenada e que suscita indignação ou ofensa universal".

Adut (2005), um dos autores que tratam da construção de escândalos, mostra quando comportamentos ilegais, criminosos, desonestos e ofensivos geram escândalos e, também, quando eles não geram, enfatizando a dimensão dramatúrgica da esfera pública. Esse autor desenvolveu uma compreensão sociológica sobre as experiências emocionais e cognitivas de escândalos, focalizando nas interações dos envolvidos ou de pessoas expostas quando esses comportamentos vêm a público. Com isso, Adut (2008) oferece um arcabouço teórico para o estudo de escândalos, independentemente de sua natureza, frequência, dinâmica, reações, efeitos e de seu uso estratégico nos diferentes sistemas sociais. Na visão do autor, os escândalos são (1) transgressões reais ou alegadas de uma norma; e que envolvem (2) a publicização de tal transgressão; levando (3) o público a reagir à esta transgressão tornada pública. Para o autor, apenas uma teoria que trate o escândalo como uma publicidade perturbadora da transgressão (seja ela real, aparente ou alegada) pode explicar a significância da aplicação da norma.

Alternativamente, Thompson (2000) propõe outra teoria dos escândalos. Para o autor, tais eventos são (1) tentativas de esconder um ato da visão do público, mas que é de conhecimento de outras pessoas; que destacam a (2) desaprovação do ato, ao mesmo tempo que fazem uma (3) denúncia pública do ato ou comportamento, com a expectativa em uma (4) probabilidade de que sua divulgação irá prejudicar a reputação dos envolvidos, além de acarretar em perdas e processos criminais. Um quinto elemento é acrescentado por Cobb e Taylor (2015), o escândalo é sustentado pela cobertura da mídia. Isso implica que um comportamento escandaloso pode não ter importância politicamente se a mídia falha na sua cobertura.

\section{A PESQUISA E O MATERIAL EMPÍRICO}

Para explorar os discursos da mídia e identificar de que modo a mídia constrói e eventualmente amplifica casos de escândalos no Brasil, especificamente envolvendo corrupção, foi selecionado o caso da Operação Lava Jato na Petrobrás. Com isso, espera-se contribuir para a compreensão de outros casos de escândalos, que envolvam corrupção. A empresa foi posicionada como protagonista de um dos maiores escândalos de corrupção do país. O caso foi observado na cobertura da mídia sobre a Operação Lava Jato, realizada nas versões online do jornal e da revista semanária de maior circulação do país, respectivamente Folha de S.Paulo e Revista Veja, conforme divulgado pelas ANJ (2015) e a ANER(2015). 
Utilizamos uma análise qualitativa, empregando uma perspectiva crítica-construtivista, por ser adequada em estudos que analisam dados da mídia (Zilber, 2006). A busca das notícias partiu da data de 18 de março de 2014, quando o esquema de corrupção veio a público, indo até 18 de março de 2015. Este recorte exclui novas informações e consequências divulgadas posteriormente sobre o caso.

Em uma fase preliminar a pesquisa nas referidas publicações utilizou a palavra-chave: “Operação Lava Jato", com o intuito de encontrar reportagens relevantes, que focalizavam o esquema de corrupção envolvendo a Petrobrás na matéria. A busca retornou 3.419 reportagens na Folha.com e 4.028 na Veja.com. Para filtrar o material, foram adicionadas complementarmente na lógica da busca as palavras-chave "corrupção" e "Petrobrás". $\mathrm{Na}$ Veja, a busca foi concentrada na seção Brasil e, na Folha, na seção Poder, pelo fato de essas duas seções serem dedicadas à cobertura política. Foram reunidas 684 e 1183 reportagens da Folha.com e da Veja.com, e selecionadas 34 e 40 reportagens, respectivamente.

O total de 74 reportagens a serem analisadas uniformemente: (1) faz menção à palavra corrupção no conteúdo da reportagem; (2) tem a Operação Lava Jato como foco da notícia, não sendo marginal; (3) o conteúdo é de cunho jornalístico, excluindo-se blogs, colunas, opiniões e material reproduzido; e (4) a extensão da reportagem é superior a duas laudas completas (a leitura prévia de textos inferiores a duas laudas identificou conteúdos repetidos e superficiais). Além das reportagens, três cadernos especiais (reportagens que têm como objetivo oferecer uma visão completa do caso) foram adicionados ao corpus de pesquisa: 1. Na trilha da Operação Lava Jato (Veja. com); 2. Entenda a Operação Lava Jato da Polícia Federal (Veja.com e Folha.com); e 3. Folha Explica - Entenda a Operação Lava Jato (Folha.com).

Nossa análise é orientada por dois pontos focais: (1) a transgressão real, ou seja, o esquema de corrupção; e (2) a produção do escândalo pela mídia. A partir desses pontos focais, nos orientamos pela conjugação das abordagens de Adut (2005); Thompson (2000) e Cobb e Taylor (2015). Com a categorização e codificação, desenvolvemos uma análise utilizando recursos da grounded theory construtivista, como propõe Charmaz (2011). Essa abordagem prioriza o fenômeno e as análises, que são construídas com base nos significados emanados do material empírico, neste caso, as reportagens selecionadas. Inicialmente, estudamos os textos, linha a linha; em seguida, selecionamos os núcleos de sentido mais relevantes para categorizá-los a partir do objetivo da pesquisa comprometido com as ideias emergentes. Na seção seguinte, apresentamos os mecanismos discursivos.

Esta pesquisa utiliza a grounded theory para responder sobre qual fenômeno os dados tratam. No processo de codificação aberta, quando os conceitos são identificados e desenvolvidos em relação às suas propriedades e dimensões (Charmaz, 2011), nós examinamos, comparamos, conceituamos e categorizamos os dados. Em seguida, na codificação axial, quando se aprimoram as categorias identificadas (Charmaz, 2011), selecionamos as categorias mais relevantes e estabelecemos relações entre elas de modo a agrupar os dados. Por fim, na codificação seletiva, cujo objetivo é integrar e refinar categorias em um nível mais abstrato (Charmaz, 2011), elaboramos a categoria essencial, a partir da qual outras categorias desenvolvidas são agrupadas. Dessa maneira, definimos que a categoria central da teoria substantiva em construção é: "mecanismos discursivos", isto é, articulações da linguagem que contribuem para a criação de sentido, pois têm a finalidade de criar a ilusão de verdade do discurso ou o efeito contrário (Zimmermann \& Silva, 2014).

\section{O CONTEXTO: Cobertura da Operação Lava Jato}

Nessa seção, recuperamos uma síntese do caso conforme noticiado nos cadernos especiais mencionados, buscando propiciar uma visão do contexto em que surgiram as matérias analisadas e os mecanismos discursivos utilizados. A Operação Lava Jato foi deflagrada pela Polícia Federal, em seis estados brasileiros e no Distrito Federal, em março de 2014, para investigar o esquema de lavagem e desvio de dinheiro envolvendo a Petrobrás, grandes empreiteiras, políticos e partidos políticos. A operação recebeu este nome por ter sido iniciada no Posto da Torre, um posto de gasolina situado a três quilômetros do Congresso Nacional, no qual não havia um lava-jato, mas, sim, uma lavanderia e uma casa de câmbio. Os investigadores consideraram que o posto desempenhava o papel de "Caixa eletrônico da propina" (VEJA.com).

O esquema funcionava com o pagamento de propinas cobradas das empreiteiras e outros fornecedores, por diretores e funcionários da Petrobrás, para facilitar seus negócios com a estatal. Outra modalidade do esquema é o superfaturamento de contratos com empresas para permitir o desvio de dinheiro da Petrobrás aos envolvidos. Lobistas, doleiros e outros operadores eram encarregados de repassar o dinheiro recebido para políticos e funcionários públicos. $\mathrm{O}$ esquema beneficiava partidos políticos responsáveis pela indicação dos diretores da Petrobrás envolvidos no esquema (Folha.com). 
Desde que o escândalo veio a público, os dois veículos analisados publicaram reportagens diariamente, não havendo um único dia sem uma publicação sobre a Operação Lava Jato. Isso caracteriza uma extensa e ampla cobertura jornalística, incluindo cadernos especiais com informações detalhadas e analíticas sobre a operação. No caso da Veja.com, um dos cadernos especiais contém 130 páginas. Além desse material, vídeos com entrevistas dos denunciados e outros envolvidos também foram disponibilizados para o público.

O caso que veio a ser conhecido como 'Petrolão' foi caracterizado pelos acordos de delação premiada que impulsionaram as investigações. Em troca de garantias de redução de penas, os envolvidos aceitaram fazer a delação sobre os crimes que participaram e fornecer provas, além de devolver os recursos auferidos na operação (Folha.com). Os principais envolvidos, segundo noticiado pela mídia analisada, são: (1) doleiros que utilizam empresas de fachada, contas em paraísos fiscais e contratos de importação fictícios para lavagem de dinheiro; (2) Petrobrás, pois os desvios em obras da estatal se tornaram o foco principal da investigação; (3) diretores da estatal que cobravam propina e repassavam o dinheiro aos políticos; (4) grandes empreiteiras, como a Odebrecht e Andrade Gutierrez; (5) políticos que receberam pagamentos de empresas sob investigação; e (6) outros setores, como o elétrico, transportes e obras, como a Usina nuclear de Angra 3 e a reforma do estágio do Maracanã (Folha. com).

\section{A CATEGORIA CENTRAL DA TEORIA: Mecanismos Discursivos}

Foram identificados dois mecanismos discursivos presentes nas matérias analisadas. O primeiro que trabalha na dimensão do evento, e o segundo que trabalha na natureza política do mesmo.

\section{"Petrolão, o maior esquema de corrupção da história do país"}

Esse primeiro mecanismo refere-se à cobertura da mídia para construir ou delinear um escândalo de proporções significativas, a fim de marcar a história do país, sobressaindo a outros esquemas de corrupção noticiados. A cobertura da mídia analisada elege o esquema de corrupção revelado como 'o maior esquema de corrupção da história do país', sem mencionar as dimensões de outros escândalos já ocorridos no país:

O que começou como uma investigação local sobre um esquema de lavagem de dinheiro operado por uma rede de doleiros acabou por trazer à luz o petrolão, maior esquema de corrupção da história do país (Veja.com, 18/01/2015).

Ao afirmarem que o "petrolão" é um dos maiores escândalos de corrupção já encontrados no mundo, líderes oposicionistas cobraram a investigação das denúncias (Folha.com, 6/2/2015).

Operação Lava Jato é a maior investigação sobre corrupção conduzida até hoje no Brasil. Ela começou investigando uma rede de doleiros que atuavam em vários Estados e descobriu a existência de um vasto esquema de corrupção na Petrobrs, envolvendo políticos de vários partidos e as maiores empreiteiras do país (Folha.com, 22/2/2015).

Os termos "petrolão" e "propinoduto" são utilizados de forma recorrente no material analisado e ambos passaram a fazer parte do vocabulário referente ao tema. A criação de neologismos, que associam o nome da Petrobrás ao esquema do mensalão (petrolão) e o termo propina com o sufixo duto (propinoduto), é uma forma de estabelecer um elo com estruturas imaginárias que criam sentido para o leitor.

Escândalos são produzidos a partir da publicização de uma transgressão, a qual pode ser real ou aparente, e sua ressonância depende da cobertura que recebem da mídia (Adut, 2005; Grü, 2008), visto sua forte influência na formação de opinião pública (Vaara et al., 2006; Clemente \& Roulet, 2015) e sua importância como fonte de construção e reprodução de realidades (Risberg et al., 2003), pois, como observa Castells (2007, p. 241), "o que não existe na mídia não existe na mente do público". Nessa perspectiva, a mídia é um componente fundamental do escândalo político, não se resumindo a acompanhar e noticiar os fatos, mas, mais que isso, tem uma participação ativa na sua ocorrência. E, em tempos que a internet reconfigurou a comunicação (Castells, 2007), ao potencializar a mídia eletrônica, a visibilidade dos fatos ganhou maior abrangência e mais velocidade, visto que a mídia tradicional adotou as versões digitais, oferecendo ao público notícias não só diárias, mas, ainda, em tempo real, tornando essa participação ainda mais ativa.

O escândalo é uma publicidade disruptiva da transgressão, portanto, ao publicizar a Operação Lava Jato como o maior escândalo do país, conferindo a ela uma cobertura extensa e ampla, a mídia enfatiza a natureza dramatúrgica da esfera pública. Adut (2008) mostra que a publicidade de um evento é uma força social capaz de transformar os significados e efeitos de uma transgressão. 
A menção de que a Operação Lava Jato investiga o maior escândalo de corrupção da história do país é recorrente nas reportagens analisadas, o que colabora para a produção do escândalo.

\title{
“Corrupção é o exercício de poder de cargos políticos”
}

O segundo mecanismo discursivo se refere à perspectiva de corrupção como um 'escândalo político', recorrente no material analisado. O esquema de corrupção envolveu políticos e seus partidos, e isso foi amplamente mencionado na cobertura da mídia analisada, indicando a perspectiva da corrupção centrada nos cargos e na autoridade. Essa perspectiva compreende a definição de Nye (1967) e de Bayley (1970) quanto a corrupção ser o mau uso da autoridade para obtenção de ganho pessoal, como é o caso dos políticos, diretores e outros funcionários envolvidos no esquema.

\begin{abstract}
Apontado como um dos principais delatores do esquema do petrolão, o doleiro Alberto Youssef disse nesta quarta-feira, em defesa apresentada à Justiça Federal, que o escândalo de lavagem de dinheiro e pagamento de propina envolvendo contratos com a Petrobras foi um projeto de «perpetuação de poder» praticado por políticos que desejavam influência «ilimitada» no cenário nacional. [...] «Agentes políticos das mais variadas cataduras racionalizaram os delitos para permanecer no poder, pois sabiam que enquanto triunfassem podiam permitir e realizar qualquer ilicitude, na certeza que a opinião pública os absolveria nas urnas», resume o doleiro (Veja.com, 28/01/2015).
\end{abstract}

O esquema de corrupção que envolve a Petrobrás é de natureza política. Na caracterização de Arseanult (2008), em um escândalo político os comportamentos dos políticos envolvidos têm o potencial de prejudicar a reputação de uma organização. No caso do Partido dos Trabalhadores (PT), o presidente do partido sugere que há uma tentativa de criminalizar o partido com denúncias falsas, e afirma que não aceitará o estigma da corrupção (Folha.com, 11/03/2015). Um escândalo político também denota que funcionários públicos podem ser acusados de usar o poder do seu cargo para obter benefícios financeiros pessoais, tais como presentes, dinheiro e contribuições para campanhas (Cobb \& Taylor, 2015), como caracterizado no caso em análise, em que o governo e partidos políticos estão imbricados.

As investigações sobre os políticos começaram em março, quando a Procuradoria-
Geral da República conseguiu autorização do STF (Supremo Tribunal Federal) e do STJ
(Superior Tribunal de Justiça) para investigar 53 pessoas, incluindo deputados federais,
senadores e dois governadores, de seis partidos políticos. Todos negam envolvimento
com o esquema. A Procuradoria decidiu que não havia elementos para abrir inquérito
sobre a presidente Dilma Rousseff, embora um dos delatores afirme que o esquema de
corrupção ajudou a financiar sua campanha eleitoral em 2010 (Folha.com, 11/03/2015).

Adut (2005) considera que o status do transgressor e de outros envolvidos é um fator importante para que uma transgressão se torne um escândalo. No material analisado, o foco no envolvimento de partidos políticos, políticos e diretores e executivos de grandes empreiteiras foi recorrente. Os escândalos políticos, conforme Castells (2007), traz implicações para o sistema político, enfraquece a credibilidade dos envolvidos influenciando a decisão de voto, e afeta a prática da democracia provocando uma crise de legitimidade política.

\section{DECLARAÇÃO FUNDAMENTAL DA TEORIA: discussão e implicações da pesquisa}

A partir do entendimento de que a mídia utiliza mecanismos discursivos para narrar os fatos provenientes de esquemas de corrupção, propõe-se a declaração fundamental da teoria: 'A mídia articula discursos de modo a construir sentidos, tornando possível a interação do leitor com as formações discursivas', em outras palavras, a mídia organiza seu discurso reinterpretando os eventos.

A análise sugere que a Operação Lava Jato se tornou um escândalo no qual a mídia delineou o significado, em que a Petrobrás se tornou o pivô do escândalo de corrupção. Nós especificamente buscamos as temáticas mais recorrentes nas abordagens das reportagens analisadas, e identificamos dois mecanismos discursivos utilizados pela Folha.com e Veja.com: "Petrolão, o maior esquema de corrupção da história do país" e a "Corrupção é o exercício de poder de cargos políticos". Esses resultados reforçam, no mínimo, três argumentos para defender que as duas abordagens (escândalos e corrupção) estão imbricadas: (1) a mídia desempenha papel crucial na repercussão do escândalo; (2) a intensidade da comunicação do escândalo na mídia analisada determina a dimensão escândalo; (3) a mídia é parcial, e, sendo assim, do mesmo modo que concedeu extrema atenção para esse caso, pode ter deixado à margem casos que poderiam ter maior repercussão financeira e, portanto, consequências mais amplas.

Dentre as consequências do escândalo, as quais atingem sociedade, indivíduos e organizações (Trasparency International, 2015; Lambsdorff, 2006) estão, desde a perda de reputação a prisões e processos criminais contra os envolvidos (indivíduos e organizações). 
Incluem-se, ainda, a desvalorização das ações da Petrobrás, bem como a desvalorização da moeda nacional. Em 31/03/2015, a Folha.Com publicou as consequências em números: 150 inquéritos abertos, 39 ações penais na Justiça Federal do Paraná, 5 ações civis para devolução de recursos desviados, 494 pessoas e empresas sob investigação, 57 políticos sob investigação no STF e no STJ, 156 réus na Justiça Federal do Paraná, 119 prisões em caráter preventivo ou temporário desde o início da operação, e, até a data da publicação, 28 pessoas presas na operação continuavam na cadeia (Folha.com).

A Folha.com publicou também a estimativa do Ministério Público Federal para o desvio dos cofres da Petrobrás: R \$ 2,1 bilhões. Em 2014, a Petrobrás estimou em R \$ 6,1 bilhões as perdas consequentes da corrupção, a partir do exame de todos os contratos com as empresas sob investigação. No caso das empreiteiras, segundo a Folha.com, as consequências da corrupção foram a prisão de executivos controladores de algumas dessas empresas, que ficaram presos de novembro de 2014 a abril de 2015. Cinco empreiteiras ainda são alvos de ações civis na Justiça e, além disso, as empresas sob investigação estão impedidas de obter novos contratos da Petrobrás e perderam acesso a crédito.

A publicização dos esquemas de corrupção pode gerar externalidades, como Adut (2005) observa: terceiros podem ser afetados e normas podem ser modificadas como resultado de reflexões e ações para resolver conflitos (Silva, 2013). No material analisado, esses dois aspectos foram mencionados. A Folha.com noticiou as medidas governamentais de um pacote anticorrupção para "punir corruptos mais rapidamente, agilizar processos contra desvios de recursos públicos e criminalizar os servidores públicos que enriquecem ilicitamente" (Folha. com, 16/03/2015), que representam potenciais ganhos que a sociedade poderia ter. Ainda, a estatal criou uma diretoria cuja atribuição é prevenir o risco de fraudes e corrupção em seus negócios, ao observar o atendimento às leis, normas, além das regras internas da Petrobrás, em todos os seus contratos e atos" (Folha.com, 13/1/2015).

Como as ocorrências de corrupção emergem nas relações do Estado, envolvendo políticos e servidores públicos agindo em nome do Estado, e indivíduos em organizações de interesse privado, diversos aspectos dessa relação deveriam ser analisados além do papel da imprensa. De um lado, valores sociais e expectativas de comportamento de gestores públicos; quais escolhas serão feitas por esses gestores na destinação de cargos comissionados e abertura de espaços para 'troca de favores', mesmo sabendo que são observados por órgãos de controle. Por outro, escândalos podem ter seus efeitos colaterais na confiança geral depositada nas instituições democráticas.

É nesta perspectiva que a sociologia dos escândalos e a sociologia da corrupção estão imbricadas: mudanças institucionais e socioculturais, muitas vezes, são originadas pelas reações da população diante dos escândalos, os quais ganham proporção ou não pela "ressonância que ganham na mídia" (Grün, 2008, p. 320), como apontam as pesquisas que articulam escândalos, corrupção e o papel desempenhado pela mídia (Grün, 2008; Tumber \& Waisbord, 2004; Castells, 2007; Toepfl, 2011). Assim, a sociologia dos escândalos apresenta-se como uma alternativa para a compreensão da corrupção, ou seja, a análise dos esquemas de corrupção pode ser realizada com base nos referenciais teóricos-analíticos dos escândalos, "não apenas para entender as condições que permitem que tais eventos transpirem, mas, também, sua emergência, interpretação e propagação" (Kuhn \& Ashcraft, 2003, p. 39), pois a "corrupção percebida não é o mesmo que escândalo, mas é a matéria-prima para a fabricação de escândalos” (Castells, 2007, p. 244).

\section{CONSIDERAÇÕES FINAIS}

Neste artigo, analisamos a publicização do esquema de corrupção revelada pela Operação Lava Jato, envolvendo Petrobrás, empreiteiras e partidos políticos. A análise mostrou de que modo a mídia construiu significados no escândalo, a Petrobrás foi posicionada no período analisado, como a protagonista "do maior escândalo de corrupção do país".

Nossa análise foi dirigida tendo como base dois pontos focais: (1) a transgressão real, ou seja, o esquema de corrupção; e (2) a produção do escândalo pela mídia. A análise desses pontos permitiu a compreensão do escândalo como a publicidade disruptiva de uma transgressão, e a identificação de dois mecanismos discursivos utilizados pela mídia, que produziram o maior escândalo de corrupção do país. Os esquemas de corrupção política são articulados por diversos atores, neste caso, diretores e funcionários da Petrobrás e de empresas privadas, políticos, lobistas e outros, formando uma teia densa que, quando revelada a público, provoca reações e manifestações que tomam proporções maiores no mesmo compasso com que a mídia realiza uma cobertura ampla e extensa, como foi o caso analisado. 
O primeiro mecanismo discursivo é “O Petrolão, maior esquema de corrupção da história do país”. Esse mecanismo discursivo é um esforço da mídia no sentido de posicionar o esquema de corrupção, que envolve a Petrobrás como o maior já existente na história do país, justificando sua extensa cobertura jornalística que compreende notícias diárias, além de cadernos especiais com explicações detalhadas. O segundo mecanismo discursivo é a compreensão da "Corrupção é o exercício de poder de cargos políticos". Um escândalo político ganha proporções maiores, pois implica que o interesse público é desvalorizado em detrimento dos ganhos privados dos políticos.

Durante a pesquisa, retomamos a literatura sobre escândalos e corrupção para fins comparativos com o material empírico. Mesmo sabendo que a corrupção é crime no país, observamos que a perspectiva legal da corrupção está ausente nas reportagens, pois não há menção ou explicação quanto aos atos cometidos sejam desvios de normas e regulamentações. Em algumas reportagens, havia a menção a "organizações criminosas", mas sem uma explicação quanto ao aspecto legal.

Os resultados apresentados contribuem para o campo dos estudos organizacionais com a compreensão das consequências da forma como os significados dos escândalos de corrupção são produzidos pela mídia. Quanto às limitações do método, destacamos a escolha de apenas dois veículos da imprensa nacional. Apesar da análise das duas fontes não permitir generalizações do comportamento de outros veículos de imprensa, o porte e o alcance nacional dos canais analisados permite vislumbrar os mecanismos discursivos associados ao escândalo de corrupção analisado. Outra limitação, é que o posicionamento ideológico-político dos veículos não foi considerado. Ambos operam conforme linhas editoriais específicas para atender as expectativas de seus públicos, porém não são levados em conta na análise.

O tema escândalos de corrupção é promissor para desenvolvimento de pesquisas no campo dos estudos organizacionais (ver Hirsch et al., 2015). Endereçamos uma agenda de pesquisas orientadas para discussão de como os discursos desenvolvidos sobre corrupção pela mídia, ao interagirem nas mídias sociais e com atores no cenário político, afetam organizações e seu capital reputacional e de mercado. No cenário brasileiro, entre estes atores seriam, além de grandes empresários e as respectivas organizações, ministros do Supremo Tribunal Federal, senadores e deputados de maior proeminência, ex-presidentes denunciados, presidente do Senado e da Câmara. Tal agenda pode contribuir com uma nova perspectiva sobre corrupção em organizações e seus impactos em governos, organizações e na sociedade como um todo.

\section{REFERÊNCIAS}

Adut, A. (2005) A Theory of Scandal: Victorians, Homosexuality, and the Fall of Oscar Wilde, American Journal of Sociology, 111(1), 213-48.

Adut, A. (2008). On scandal. Moral Disturbances in Society, Politics, and Art. New York: Cambridge University Press.

Amundsen, I.(1999). Political Corruption: an introduction to the issues. Bergen: Chr. Michelsen Institute.

ANER.Circulação. Revistas Semanais. Recuperado de http://aner.org.br/dados-de-mercado/circulacao/.

ANJ.Maiores jornais do Brasil. Ano 2014. Recuperado de http://www.anj.org.br/maiores-jornais-do-brasil/.

Arsenault, A. (2008). Scandal Politics in the New Media Environment. Analytical Note. Spring 2008. Disponível em: https://www.academia.edu/444255/SCANDAL_POLITICS_IN_THE_NEW_MEDIA_ENVIRONMENT_ Analytical_Note_Spring_2008.

Ashforth, B.E., Gioia, D.A., Robinson, S. L., \& Treviño, L.K.(2008). Re-Viewing Organizational Corruption. Academy of Management Review, 33(3), 670-684.

Azevedo, F. (2010). Corrupção, mídia e escândalos midiáticos no Brasil. Em Debate, Belo Horizonte, 2(3), 14-19.

Batabyal, S., \& Chowdhury, A.(2015). Curbing corruption, financial development and income inequality. Progress in Development Studies, 15(1), 49-72

Bayley, D.H.(1970). The effects of corruption in a developing nation. In: Heidenheimer, A. J. Political corruption - readings in compara tive analysis. New York, Holt, Rinehart and Winston.

Castells, M.(2007). Communication, Power and Counter-power in the Network Society. International Journal of Communication, 1(2007), 238-266. 
Charmaz, K. (2011). Grounded Theory Methods in Social Justice Research. In: Denzin, N. K. \& Lincoln, Y. E. Handbook of Qualitative Research. London: Sage Publications.

Clemente, M., \& Roulet, T.K.(2015). Public Opinion as a source of desinstitutionalization: A "spiral of silence" approach. Academy of Management Review, 40(1), 96-114.

Cobb, M.D., \& Taylor, A.J. (2015). An Absence of Malice: The Limited Utility of Campaigning Against Party Corruption, American Politics Research, 43(6), 923 -951.

Connelly, B.S., \& Ones, D.S. (2008). The Personality of Corruption A National-Level Analysis. Cross-Cultural Research, 42 (4), 353-385.

Esser, F., \& Hartung, U. (2004) Nazis, Pollution, and no Sex: Political Scandals as a Reflection of Political Culture in Germany. American Behavioral Scientist , 47(8), 1040-1071.

Gardiner, J. A. (1970) The politics of corruption in an American city. In: Heidenheimer, A. J. Political corruption - readings in comparative analysis. New York, Holt, Rinehart and Winston.

GPAC-Global Programme Against Corruption.(2001). United Nations Manual on Anti-Corruption Policy. Recuperado de http://www.unodc.org/pdf/crime/gpacpublications/manual.pdf.

Grün, R. (2008). Escândalos, Marolas e Finanças: Para uma sociologia da transformação do ambiente econômico. Revista de Ciências Sociais, 51(2), 313-352.

Heidenheimer, A.J. (1970). The context of analysis. In: Heidenheimer, A. J. Political corruption readings in comparative analysis. New York, Holt, Rinehart and Winston.

Hirsch, P., Holan, P. M., Philips, N., \& Zyglidopoulos, S. (2015). Special Issue of Journal of Management Inquiry: Corruption, Management and Organizations, Journal of Management Inquiry, Call for papers, Disponível em: http:/omtweb.org/announcements/calls-for-papers/634-special-issue-of-journal-of-management-inquirycorruption-management-and-organizations

Hodgkinson, P. (1997). The sociology of corruption -some themes and issues. Sociology, 31 (1), 17-35.

Holan, P.M., Zyglidopoulos, S., \& Hirsch, P. (eds)(2017). Special Issue: Corruption Part 1. Journal of Management Inquiry, 26(3), 247-347.

Jacobsson, K., \& Löfmarck, E. (2008) A Sociology of Scandal and Moral Transgression The Swedish 'Nannygate'Scandal. Acta Sociologica, 51(3), 203-216.

Kuhn, T., \& Ashcraft, K.L. (2003). Corporate Scandal And The Theory Of The Firm- Formulating the Contributions of Organizational Communication Studies. Management Communication Quarterly, 17(1), 20-57.

Lambsdorff, J.G.(2006). Causes and consequences of corruption: What do we know from a cross-section of countries? In: Rose-Ackerman, S. International Handbook on the economics of corruption. Edward Elgar Publish, Inc, Northampton, Massachusetts.

Maeda, R., \& Ziegfeld, A.(2015). Socioeconomic status and corruption perceptions around the world. Research and Politics, 1-9, Doi:10.1177/2053168015580838.

Numerato, D. (2015). Corruption and public secrecy: An ethnography of football match-fixing. Current Sociology, 1 -19. DOI: $10.1177 / 0011392115599815$.

Nye, J. S.(1967). Corruption and political development: a coast-benefit analysis. American Political Science Review, 61(2), 417-27.

Oberoi, R. (2014). Mapping the Matrix of Corruption: Tracking the Empirical Evidences and Tailoring Responses. Journal of Asian and African Studies, 49(2), 187 -214.

O'Connor, S., \& Fischer, R. (2012). "Predicting Societal Corruption Across Time: Values, Wealth, or Institutions?”, Journal of Cross-Cultural Psychology, 43(4), 644-659.

Power, T.J., \& Gonzáles, J. (2003). Cultura Política, Capital Social E Percepções Sobre Corrupção: Uma Investigação Quantitativa Em Nível Mundial. Rev. Sociol. Polít., Curitiba, 21, 51-69.

Risberg, A., Tineri, J., \& Vaara, E. (2003). Making sense of a transnational merger: media tets and the (re) construction of power relatins. Culture and organization, 9(2), 121-137. 
Silva, T. (2013). A pesquisa sobre escândalo político: panorama de 10 anos. Revista Fronteiras - estudos midiáticos, $15(3), 160-169$.

Simmel, G. (1906). The sociology of secrecy and of secret societies. American Journal of Sociology, 11(4), 441498.

Thompson, J. B. (2000). Political scandal: Power and visibility in the media age. Cambridge, MA: Polity Press.

TI.Transparency International. Unmask the corrupt. Recuperado de http:/www.transparency.org/.

Toepfl, F. (2011). Managing public outrage: Power, scandal, and new media in contemporary Russia. New Media \& Society, 13(8), $1301-1319$.

Tumber, H. \& Waisbord, S. R. (2004). Political scandals and media across democracies volume II. The American Behavioral Scientist, 47(9), 1143-1152.

Vaara, E.; Tenri, J., \& Laurila, J. (2006). Pulp and paper fiction: on the discursive legitimation of global industrial restructuring. Organization studies, 27(6), 789-813.

Warren, M.E. (2001). Social capital and corruption. Annual Review of Sociology, 24(1), 1-24.

World Bank.(2006). Engaging with fragile states: An IEG review of World Bank support to low-income countries under stress. Washington, DC: The World Bank. Recuperado de www.worldbank.org/ieg.

Zilber, T.B.(2006).The work of the symbolic in institutional processes: translations of rational myths in Isareli hight tech. Academy of Managemnet Journal, 49(2), 291-303.

Zimmermann, N., \& Silva, H. C da. (2014). O Mecanismo De Antecipação Aplicado À Análise Discursiva De Entrevistas: Imaginários De Leitura De Professores Na Educação Científica. Ensaio Pesquisa em Educação em Ciências (Belo Horizonte), 16(2), 33-52.

\section{APÊNDICE: lista de fontes de mídia citadas no documento}

Folha.com, 13/01/2015 < http://www1.folha.uol.com.br/poder/2015/01/1574568-petrobras-escolhe-diretor-denova-area-de-prevencao-de-fraudes.shtml $>$

Folha.com, 06/02/2015 <http:/www1.folha.uol.com.br/poder/2015/02/1585865-oposicao-cobra-investigacao-depropina-que-teria-sido-recebida-pelo-pt.shtml>

Folha.com, 22/02/2015 < http://www1.folha.uol.com.br/poder/2016/02/1741802-policia-federal-inicia-23-faseda-operacao-lava-jato.shtml>

Folha.com, 11/03/2015 <http:/www1.folha.uol.com.br/fsp/poder/211412-lula-se-queixa-de-vazamento-seletivodas-investigacoes.shtml>

Folha.com, 16/03/2015 <http://www1.folha.uol.com.br/poder/2015/03/1603461-pacote-do-governo-vai-punircorruptos-mais-rapidamente-diz-cardozo.shtml $>$

Folha.com, 31/03/2015<http://arte.folha.uol.com.br/poder/operacao-lava-jato/>

Veja.com, 18/01/2015 <https://veja.abril.com.br/politica/lava-jato-ja-e-uma-referencia-diz-delegada/>

Veja.com, 28/01/2015<https://veja.abril.com.br/politica/petrolao-foi-projeto-de-perpetuacao-de-poder-depoliticos-diz-youssef/> 